\title{
Perancangan Aplikasi Presensi Dosen Realtime Dengan Metode Rapid Application Development (RAD) Menggunakan Fingerprint Berbasis Web
}

\author{
Darma Setiawan Putra ${ }^{\left.1^{*}\right)}$, Ami Fauzijah ${ }^{2}$ \\ 1,2 Jurusan Teknik Informatika Politeknik Aceh Selatan \\ 1,2Jalan Merdeka, Kompleks Reklamasi Pantai, Tapaktuan, Aceh Selatan \\ email : ${ }^{1}$ darmasetiawan@poltas.ac.id, ${ }^{2}$ amifauzijah@gmail.com \\ Received: 20 Meret 2018; Revised: 8 Mei 2018; Accepted: 13 Mei 2018 \\ Copyright @2018 Politeknik Harapan Bersama Tegal. All rights reserved
}

\begin{abstract}
The fingerprint is one of the biometric methods which is can be used in the education field. Attendance monitoring system using fingerprint will make the leaders easily to monitor the attendance of the lecturer and to make decisions. The fingerprint attendance is used to easy students detecting quickly and accurately the lecturer in the classroom. This system aims to provide the lecturer status information, entry or exit for teaching when every lecturer performs a fingerprint scanning. This study uses rapid application development (RAD) method to develop attendance system and involves the lecturer who have a teaching schedule in the current semester. To test the system, the lecturer was required to record the fingerprint in fingerprint machine. The result shows that the application of lecturer attendance in real time web-based can be a system provides the lecturers attendance information effectively and efficiently.
\end{abstract}

Abstrak - Sidik jari (fingerprint) merupakan salah satu metode biometrik yang dapat digunakan di dunia pendidikan. Presensi yang menggunakan sidik jari secara real time akan mempermudah para pimpinan untuk melakukan monitoring kehadiran dosen untuk mengajar dan mengambil keputusan. Presensi sidik jari ini juga dapat mempermudah mahasiswa untuk mengetahui kehadiran dosen di kelas secara cepat dan akurat. Sistem ini bertujuan untuk memberikan informasi status dosen masuk atau keluar mengajar ketika setiap dosen melakukan scan sidik jari. Penelitian ini menggunakan metode rapid application development (RAD) dalam pengembangan sistem presensi kehadiran dan dilakukan dengan melibatkan dosen yang memiliki jadwal mengajar pada semester berjalan. Dalam pengujian sistem, dosen diminta untuk melakukan perekaman sidik jari dengan mesin sidik jari. Hasil penelitian ini menunjukkan bahwa aplikasi presensi dosen secara real time berbasis web ini dapat dijadikan sebagai suatu sistem yang memberikan informasi kehadiran dosen secara efektif dan efisien.

Kata kunci - Presensi, Sidik Jari, Biometrik, Realtime, Monitoring.

*) Corresponding author: Darma Setiawan Putra

Email: darmasetiawan@poltas.ac.id

\section{PENDAHULUAN}

Ilmu pengetahuan dan teknologi yang telah berkembang pada saat ini telah memberikan dampak yang cukup siginifikan pada instansi pendidikan. Mekanisme yang dapat mengukur kinerja sangat dibutuhkan agar pelayanan yang dapat diberikan menjadi lebih baik. Salah satu metode yang digunakan untuk mengukur kinerja pegawai adalah adanya presensi kehadiran [1][2]. Presensi dengan cara manual yaitu dengan cara mengisi form pengisian menjadi tidak efektif karena cara tersebut sangat mudah dimanipulasi sehingga data kehadiran seseorang ditempat kerja tidak akan terjaga keasliannya [3]. Presensi kehadiran merupakan salahsatu penunjang yang dapat mendukung aktifitas dan kegiatan dalam bidang pendidikan terutama dalam proses belajar mengajar [4][5]. Teknologi sidik jari (fingerprint) adalah suatu alat yang dapat digunakan untuk memberikan kemudahan dalam presensi kehadiran dan untuk menghindari adanya manipulasi data presensi [6]. Pencatatan kehadiran dosen dalam proses belajar mengajar adalah hal yang wajar dan secara umum dilakukan dengan menandatangani lembar kehadiran. Monitoring kehadiran dosen menggunakan sidik jari merupakan salahsatu pendekatan yang ditempuh dalam rangka meningkatkan performa pegawai. Presensi berbasis fingerprint merupakan suatu teknologi yang sedang marak dan sangat mendukung dikarenakan penerapannya mudah dan terjangkau [7].

Dalam studi ini akan dibuat suatu sistem informasi presensi dosen yang berbasis web dan dapat disajikan secara realtime. Ketika mesin sidik jari membaca sidik jari setiap dosen saat masuk dan keluar ruangan kelas maka sistem presensi ini akan membaca kode dosen sesuai dengan kode sidik jari untuk setiap dosen yang telah disimpan dalam database dan selanjutnya akan diberikan informasi status dosen. Status dosen pada saat masuk dan keluar ruangan mengajar akan ditampilkan pada halaman web dan secara otomatis akan ditampilkan juga pada layar monitor. Dengan adanya sistem presensi ini akan memudahkan bagi pimpinan untuk mengambil keputusan secara cepat dan akurat. 


\section{PENELITIAN YANG TERKAIT}

Beberapa cara telah dilakukan oleh peneliti sebelumnya untuk melakukan presensi kehadiran baik yang menggunakan biometrik maupun menggunakan kode. Peneliti ini [8] telah melakukan penelitian untuk melakukan presensi kehadiran dengan memanfaatkan kode $Q R$-code sebagai pendeteksi kehadiran mahasiswa yang ditampilkan pada smartphone selama perkuliahan. Setiap mahasiswa akan melakukan deteksi kode $Q R$-code untuk mengkonfirmasi kehadirannya. Peneliti selanjutnya [9] melakukan penelitian untuk mengetahui bagaimana pengenalan sidik jari dapat digunakan sebagai identifikasi seseorang. Penelitian ini juga menghasilkan bagaimana sidik jari dapat digunakan sebagai sistem presensi kehadiran yang dihubungkan dengan jaringan GSM sehingga kehadiran siswa dapat diinformasikan kepada orangtua.

Peneliti selanjutnya [10] telah melakukan penelitian dimana metode untuk mengetahui kehadiran mahasiswa selama perkuliahan adalah dengan menggunakan kode biometrik sidik jari. Hasilnya menunjukkan bahwa sistem presensi kehadiran mahasiswa yang menggunakan metode biometrik akan membuat kinerja menjadi meningkat bila dibandingkan dengan sistem presensi dengan metode manual. Peneliti berikutnya [9] telah melakukan penelitian sistem manajemen kehadiran mahasiswa dengan menggabungkan sidik jari dengan RFID. Hasilnya menunjukkan bahwa dari sisi performa dan efisiensi, sistem ini sangat mudah untuk menandai kehadiran mahasiswa bila dibandingkan dengan metode manual. Pada penelitian ini, kami merancang sebuah aplikasi presensi dosen dengan menggunakan deteksi sidik jari (fingerprint) yang dapat tersaji secara realtime pada laman web yang ditampilkan pada layar monitor sehingga kehadiran dosen dikelas dapat diketahui oleh mahasiswa dan para pengambil kebijakan.

\section{A. Pengembangan Sistem}

Penelitian ini dilakukan dengan menggunakan metode Rapid Application Development (RAD). Menurut Kendall [11], RAD merupakan suatu metode pengembangan perangkat lunak dengan pendekatan berorientasi objek (object oriented approach) terhadap pengembangan sistem. Metode ini bertujuan untuk mempersingkat waktu dalam perencanaan, perancangan dan penerapan suatu sistem bila dibandingkan dengan metode tradisional. Gbr 1 menunjukkan siklus RAD dengan 3 (tiga) fase dalam perencanaan, perancangan dan penerapan sistem yang melibatkan analis dan pengguna.

Pada tahap perencanaan, pengguna dan analis akan bertemu untuk mengidentifikasi tujuan sistem dan juga mengidentifikasi syarat-syarat informasi yang muncul dari tujuan tersebut. Pada fase ini, orientasi akan menyelesaikan masalah pengguna. Pada tahap perancangan, analis dan pengguna akan bekerjasama untuk merancang dan membangun sistem. Tahap ini dapat dilakukan selama beberapa hari tergantung ukuran aplikasi yang akan dikembangkan. Dalam tahap ini juga, pengguna akan merespon prototype yang ada dan analis akan memperbaiki rancangan berdasarkan masukan dan respon dari pengguna. Pola kerja ini akan mendorong pengembangan hingga tingkat akhir. Pada tahap penerapan, analis yang telah bekerja secara intensif selama tahap perencanaan dan perancangan kemudian disetujui oleh pengguna maka sistem baru akan diujicoba dan diperkenalkan kepada organisasi.

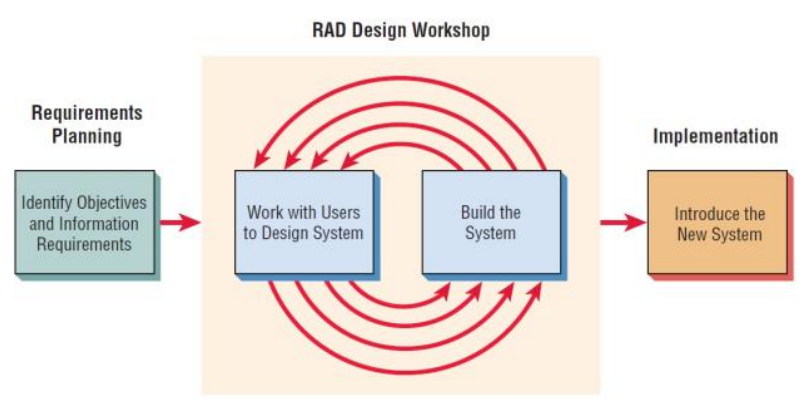

Gbr. 1 Siklus RAD [11]

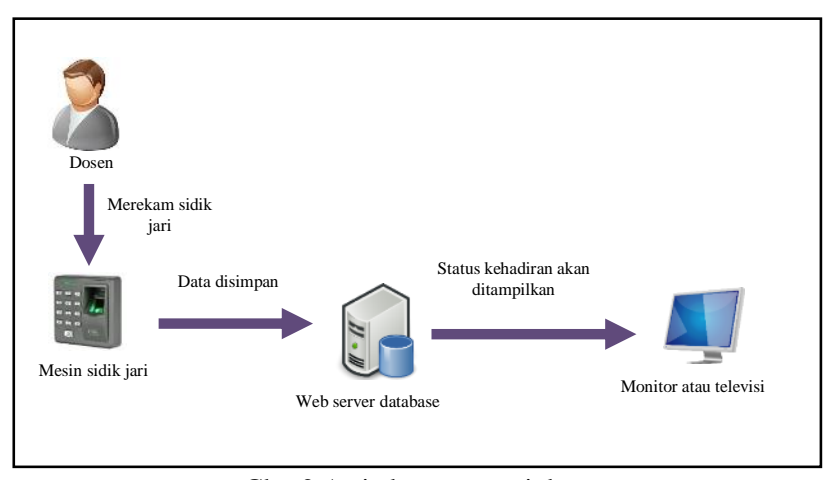

Gbr. 2 Arsitektur presensi dosen

\section{B. Arsitektur Sistem Presensi}

Adapun arsitektur presensi dosen berbasis web sebagaimana ditunjukkan oleh Gbr. 2. Setiap dosen akan melakukan registrasi sidik jari dengan menggunakan mesin sidik jari pada tahap awal. Ketika dosen masuk mengajar, dosen melakukan deteksi (scan) sidik jari yang diletakkan pada mesin sidik jari. Aplikasi ini akan membaca kode sidik jari yang telah sukses dideteksi dan dicocokkan dengan yang ada dalam database. Selanjutnya informasi kehadiran dosen akan ditampilkan pada layar televisi atau monitor secara otomatis.

Adapun diagram alir (flowchart) untuk melakukan deteksi sidik jari dosen sebagaimana ditunjukkan oleh Gbr. 3 yang menjelaskan bahwa ketika mesin fingerprint membaca sidik jari dosen maka mesin fingerprint akan membandingkan antara kode sidik jari yang berhasil dideteksi dengan kode sidik jari yang ada di dalam database. Setiap kode sidik jari ini akan diberikan dalam bentuk nomor id dosen. Jika perbandingan tersebut adalah sama maka nomor id dosen akan dikenali oleh sistem dan jika perbandingan tersebut tidak sama maka nomor id dosen tidak akan dikenali oleh 
sistem dan sistem akan meminta kembali kepada dosen untuk melakukan deteksi ulang. Nomor id dosen yang telah dikenali tersebut akan dicocokkan dengan nomor id dosen yang ada dalam database jadwal mengajar. Jika nomor id dosen pada database mengajar ditemukan maka sistem akan menampilkan status dosen di layar televisi atau monitor dan jika nomor id dosen pada database mengajar tidak ditemukan maka sistem tidak akan menampilkan status dosen di layar televisi atau monitor.

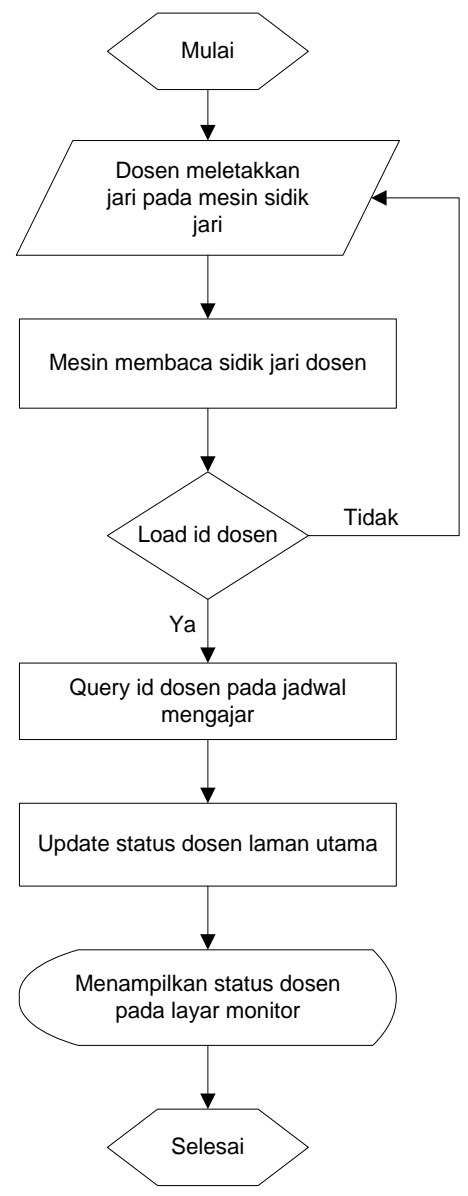

Gbr. 3 Diagram alir sistem presensi dosen

\section{Implementasi sistem presensi}

Sistem presensi dosen ini diimplementasikan pada Politeknik Aceh Selatan. Presensi dilakukan pada saat dosen masuk dan keluar mengajar. Mesin sidik jari ini akan mengirimkan data sidik jari dosen ke database yang ada pada webserver. Admin dapat melakukan pengaturan data pengguna. Kebutuhan perangkat keras dalam membangun sistem presensi ini adalah mesin sidik jari, komputer PC dan layar monitor sedangkan kebutuhan perangkat lunak adalah XAMPP versi 3.2.2 dan pemograman PHP 5.

\section{Pengambilan sampel data}

Proses pengumpulan data dilakukan dengan melibatkan dosen yang ada di Politeknik Aceh Selatan. Setiap dosen melakukan proses penginputan data sidik jari terlebih dahulu menggunakan jari yang sama. Setiap sampel diminta untuk merekam sidik jari sebanyak 3 kali dengan menggunakan jari yang nyaman bagi dosen.

Jumlah pengambilan data sidik jari dengan mesin sidik jari sebanyak 3 kali ini bertujuan untuk menjaga agar sampel sidik jari mampu mewakili data sidik jari setiap dosen. Data sidik jari inilah yang akan disimpan ke dalam database sidik jari sebagai data pembanding ketika dosen melakukan scanning sidik jari pada saat masuk dan keluar mengajar. Proses pengambilan data sidik jari seperti ditunjukkan oleh Gbr. 4.

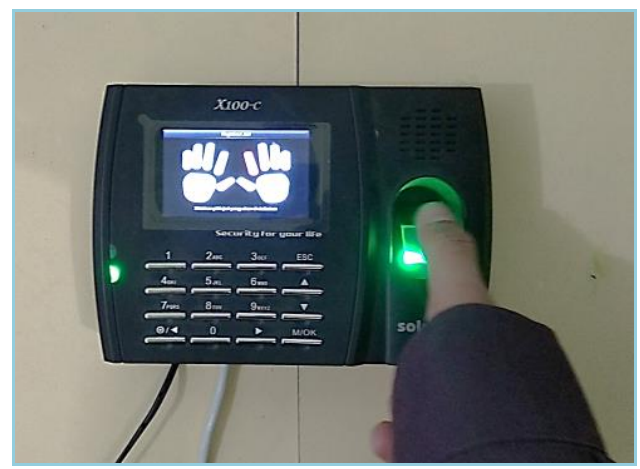

Gbr. 4 Proses pengambilan data sidik jari

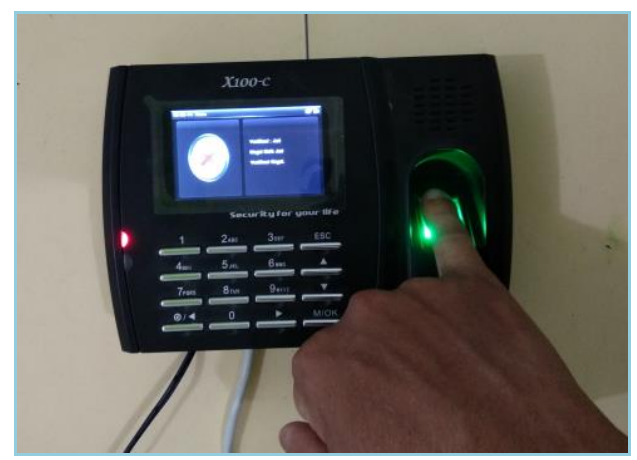

Gbr. 5 Scanning sidik jari mengalami kegagalan

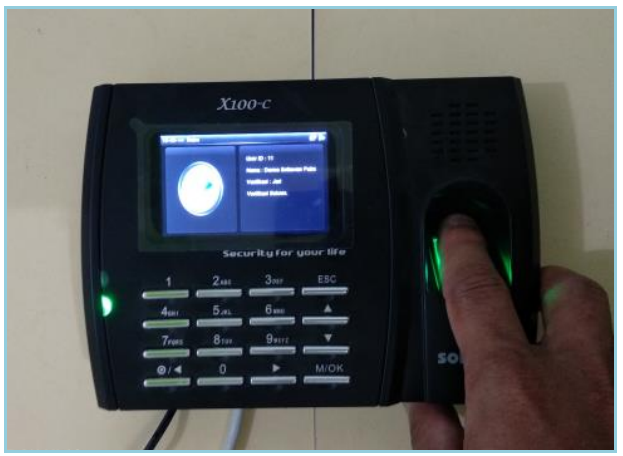

Gbr. 6 Scanning sidik jari dinyatakan berhasil 


\section{HASIL DAN PEMBAHASAN}

\section{A. Pengujian sistem presensi}

Untuk melakukan presensi, setiap dosen meletakkan jari tangan yang telah terdaftar pada sensor yang ada pada mesin fingerprint. Jika hasil scan sidik jari tidak cocok dengan data yang ada di dalam database maka presensi dinyatakan gagal dan sebaliknya jika hasil scan sidik jari cocok dengan data yang ada di dalam database maka presensi dinyatakan berhasil. Gbr. 5 menunjukkan proses scanning sidik jari mengalami kegagalan dan Gbr. 6 menunjukkan proses scanning sidik jari dinyatakan berhasil.

\section{B. Waktu presensi}

Presensi dilakukan pada saat masuk dan keluar mengajar. Secara umum, waktu presensi diatur pada pukul 07.00 WIB hingga pukul 18.00 WIB. Waktu tersebut adalah rentang waktu untuk melakukan sidik jari. Apabila dosen melakukan presensi sebelum jam 07.00 WIB dan setelah jam 18.00 WIB maka sistem presensi akan menolak. Kehadiran dan ketidakhadiran dosen akan ditampilkan pada saat melakukan presensi dalam rentang waktu tersebut dan sesuai dengan jadwal mengajar untuk setiap dosen. Dosen melakukan scan sidik jari sebelum jadwal mengajar maka status dosen adalah IN (masuk) dan dosen kembali melakukan scan sidik jari setelah jadwal mengajar maka status dosen adalah OUT (keluar).

\section{Antarmuka aplikasi presensi}

Antarmuka yang digunakan untuk mengetahui kehadiran dosen lengkap dengan tanggal, nomor id dosen, jam masuk ruangan, jam keluar dari ruangan dan status dosen sebagaimana ditunjukkan oleh Gbr. 7. Dan tampilan yang digunakan untuk memberikan informasi presensi dosen secara real time dapat menggunakan layar televisi atau layar monitor. Layar televisi dapat digunakan untuk memberikan informasi kehadiran dosen untuk seluruh mahasiswa baik status dosen sedang mengajar di kelas ataupun sudah keluar dari kelas.

Sedangkan layar monitor komputer dapat digunakan untuk mengetahui status dosen sedang berada di ruang kelas atau keluar dari ruang kelas sesuai dengan jadwal mengajar yang telah ditentukan bagi ketua program studi dan pimpinan. Seorang operator ditunjuk untuk memantau dan menjaga agar aplikasi dapat berjalan dengan baik dan ketika terjadi masalah dapat ditangani dengan cepat.
Rancangan hubungan antara layar televisi, layar monitor komputer dan mesin sidik jari sebagaimana diperlihatkan oleh Gbr. 8.

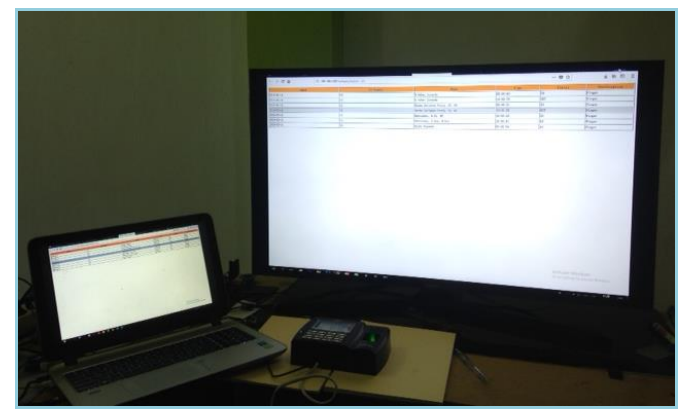

Gbr. 8 Koneksi antara layar televisi, komputer dan mesin sidik jari

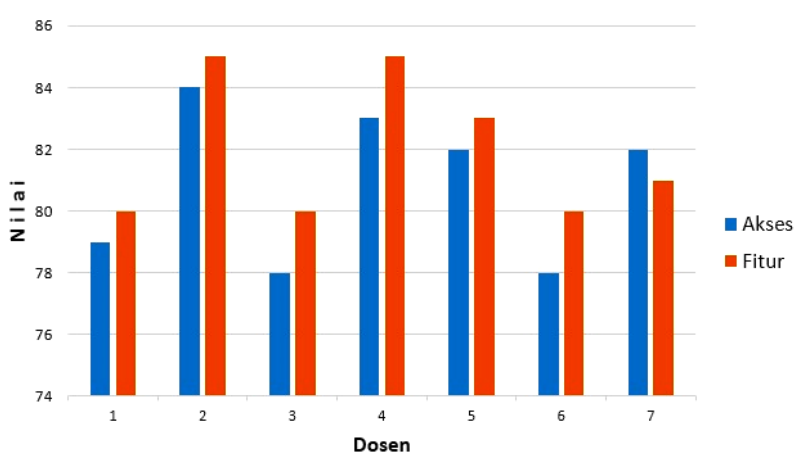

Gbr. 9 Grafik pengujian sistem presensi dosen

Gbr. 9 menunjukkan grafik dari hasil pengujian sistem yang dilakukan oleh dosen berdasarkan 2 kriteria penilaian yaitu kriteria kecepatan respon (akses) pada saat mesin sidik jari mendeteksi sidik jari dan kriteria fitur yang disajikan pada tampilan dari sistem presensi dosen ini.

\section{KESIMPULAN}

Dari hasil dan pembahasan yang telah disampaikan pada pembahasan dapat disimpulkan bahwa sistem manajemen sidik jari yang terintegrasi dengan jadwal mengajar dan status dosen secara realtime telah memberikan bantuan kepada pimpinan untuk memperoleh informasi presensi dosen secara secara cepat dan akurat. Sistem ini dapat berjalan sesuai

\begin{tabular}{|c|c|c|c|c|c|}
\hline$\leftarrow \rightarrow \mathrm{C}$ 会 & (i) $192.168 .1 .201 / \mathrm{cs} /$ query?action=run & & & $\cdots \nabla \hat{~}$ & $\underline{\underline{4}} \quad$ III \\
\hline Date & ID Number & Name & Time & Status & Verification \\
\hline 2018-03-14 & 10 & S Fahmi Junanda & $08: 00: 42$ & IN & Finger \\
\hline $2018-03-14$ & 10 & S Fahmi Junanda & $10: 00: 29$ & OUT & Finger \\
\hline 2018-03-14 & 11 & Darma Setiaman Putra, ST, MT & 08:00:31 & IN & Finger \\
\hline $2018-03-14$ & 11 & Darma Setiawan Putra, ST, MT & $10: 01: 33$ & OUT & Finger \\
\hline 2018-03-14 & 12 & Bakruddin, S.Si, MT & 10:00:58 & IN & Finger \\
\hline $2018-03-14$ & 13 & Rhairuman, S. Rom, M. Kou & $10: 00: 47$ & IN & Finger \\
\hline 2018-03-14 & 14 & Hasbi Gunaran & $08: 00: 54$ & IN & Finger \\
\hline
\end{tabular}

Gbr. 7 Halaman utama presensi dosen 
dengan fungsinya jika setiap dosen melakukan deteksi sidik jari pada saat sebelum masuk ruangan dan kembali melakukan deteksi sidik jari setelah keluar ruangan. Dosen yang melakukan deteksi sidik jari tidak sesuai dengan jadwal masuk dan keluar mengajar akan langsung diketahui oleh pimpinan. Adapun tahap pengembangan presensi dosen ini selanjutnya adalah sistem ini perlu ditambahkan dengan deteksi iris mata sehingga tingkat pemalsuan kehadiran dosen dapat dicegah dan dikurangi seminimal mungkin.

\section{UCAPAN TERIMAKASIH}

Penulis menyampaikan ucapan terima kasih kepada Lembaga Penelitian dan Pengabdian Masyarakat (LPPM) Politeknik Aceh Selatan (Poltas) yang telah memberikan dana hibah untuk membiayai penelitian ini.

\section{DAFTAR PUSTAKA}

[1] Junaidi, L. Anugrah, and A. D. Pancasakti, "Model Aplikas Monitoring Sistem Absensi Sidik Jari Sebagai Pendukung Keputusan Untuk Penilaian Kinerja Pegawai,” Konf. Nas. Sist. dan Inform., pp 9-10, 2015.

[2] H. Jusuf, A. Azimah, and Winarsih, "Pengembangan Aplikasi Sistem Absensi Dosen dengan Menggunakan Fingerprint (Sidik Jari Digital) di Universitas Nasional," Rekayasa Teknol. J., vol. 5, no. 1, pp. 3-8, 2013.
[3] C. F. A. Sari and L. Yulianto, "Perancangan Sistem Informasi Absensi Menggunakan Finger Print di Badan Perencanaan Pembangunan Daerah dan Penanaman Modal Kabupaten Pacitan," Semin. Ris. Unggulan Nas. Inform. dan Komput. FTI UNSA, vol. 2, no. 1, pp. 1-7, 2013.

[4] A. S. Rintjap, S. R. . A, Sompie, and O. Lantang, "Aplikasi Absensi Siswa Menggunakan Sidik Jari di Sekolah Menengah Atas Negeri 9 Manado," e-Journal Tek. Elektro dan Komput., pp. 1-5, 2014.

[5] M. Akbar and I. Effendy, "Implementasi Aplikasi Kehadiran Perkuliahan Dikelas Menggunakan Pembaca RFID Pada e-KTP," $J$ Inform. J. Pengemb. IT, vol. 3, no. 1, pp. 31-35, 2017.

[6] A. Irawan, I. F. Astuti, and D. Cahyadi, "Presensi Sidik Jari (Fingerprint) Berbasis Web Service (Studi Kasus: Fakultas MIPA Universitas Mulawarman)," Pros. Semin. Sains dan Teknol. FMIPA Unmul, vol. 1, no. 1, 2015.

[7] N. A. Muhammad, F. Samopa, and R. P. Wibowo, "Pembuatan Aplikasi Presensi Perkuliahan Berbasis Fingerprint (Studi Kasus Jurusan Sistem Informasi Institut Teknologi Sepuluh November Surabaya),"J. Tek. POMITS, vol. 2, no. 3, 2013.

[8] F. Masalha and N. Hirzallah, "A Students Attendance System Using QR Code,” Int. J. Adv. Comput. Sci. Appl., vol. 5, no. 3, pp. 75-79, 2014.

[9] K. Jaikumar, M. S. Kumar, S. Rajkumar, and A. Sakthivel, "Fingerprint Based Student Attendance System with SMS Alert to Parents," Int. J. Res. Eng. Technol., vol. 4, no. 2, pp. 293-297, 2015.

[10] O. Shoewu, N. T. Makanjuola, and S. O. Olatinwo, "Biometric-based Attendance System: LASU Epe Campus as Case Study," Am. J. Comput. Res. Repos., vol. 2, no. 1, pp. 8-14, 2014.

[11] K. E. Kendall and J. E. Kendall, System Analysis and Design, Eight Edit. New Jersey: Prentice Hall, 2011. 